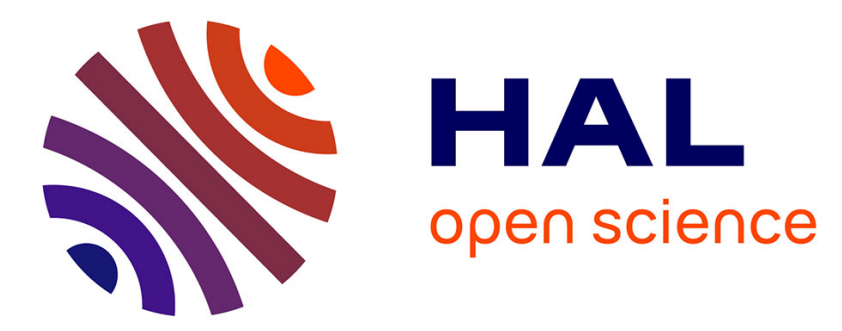

\title{
Determination of a new uniform thorax density representative of the living population from 3D external body shape modeling
}

Célia Amabile, Julie Choisne, Agathe Nerot, Hélène Pillet, Wafa Skalli

\section{- To cite this version:}

Célia Amabile, Julie Choisne, Agathe Nerot, Hélène Pillet, Wafa Skalli. Determination of a new uniform thorax density representative of the living population from 3D external body shape modeling. Journal of Biomechanics, 2016, 49 (7), pp.1162-1169. 10.1016/j.jbiomech.2016.03.006 . hal-01738688

\section{HAL Id: hal-01738688 \\ https://hal.science/hal-01738688}

Submitted on 15 Apr 2020

HAL is a multi-disciplinary open access archive for the deposit and dissemination of scientific research documents, whether they are published or not. The documents may come from teaching and research institutions in France or abroad, or from public or private research centers.
L'archive ouverte pluridisciplinaire HAL, est destinée au dépôt et à la diffusion de documents scientifiques de niveau recherche, publiés ou non, émanant des établissements d'enseignement et de recherche français ou étrangers, des laboratoires publics ou privés. 


\title{
Determination of a new uniform thorax density representative of the living population from 3D external body shape modeling
}

\author{
Celia Amabile ${ }^{\mathrm{a}, \mathrm{b}, *}$, Julie Choisne ${ }^{\mathrm{a}}$, Agathe Nérot ${ }^{\mathrm{a}, \mathrm{c}}$, Hélène Pillet ${ }^{\mathrm{a}}$, Wafa Skalli ${ }^{\mathrm{a}}$ \\ a Arts et Métiers ParisTech, LBM/Institut de Biomécanique Humaine Georges Charpak, Paris, France \\ ${ }^{\mathrm{b}}$ Spine Service, Hospital for Special Surgery, 535 East 70th Street, Belaire 4-E, New York, NY 10021, USA \\ ' UMR_T9406, LBMC Laboratoire de Biomécanique et Mécanique des Chocs, IFSTTAR, Bron, France
}

Keywords:

Thorax density

Body segment parameters Rib

cage volume

Thorax volume

\begin{abstract}
A B S T R A C T
Body segment parameters (BSP) for each body's segment are needed for biomechanical analysis. To provide population-specific BSP, precise estimation of body's segments volume and density are needed. Widely used uniform densities, provided by cadavers' studies, did not consider the air present in the lungs when determining the thorax density. The purpose of this study was to propose a new uniform thorax density representative of the living population from 3D external body shape modeling. Bi-planar $\mathrm{X}$-ray radiographies were acquired on 58 participants allowing 3D reconstructions of the spine, rib cage and human body shape. Three methods of computing the thorax mass were compared for 48 subjects: (1) the Dempster Uniform Density Method, currently in use for BSPs calculation, using Dempster density data, (2) the Personalized Method using full-description of the thorax based on 3D reconstruction of the rib cage and spine and (3) the Improved Uniform Density Method using a uniform thorax density resulting from the Personalized Method. For 10 participants, comparison was made between the body mass obtained from a force-plate and the body mass computed with each of the three methods. The Dempster Uniform Density Method presented a mean error of $4.8 \%$ in the total body mass compared to the force-plate vs $0.2 \%$ for the Personalized Method and $0.4 \%$ for the Improved Uniform Density Method The adjusted thorax density found from the 3D reconstruction was $0.74 \mathrm{~g} / \mathrm{cm}^{3}$ for men and $0.73 \mathrm{~g} / \mathrm{cm}^{3}$ for women instead of the one provided by Dempster $\left(0.92 \mathrm{~g} / \mathrm{cm}^{3}\right)$, leading to a better estimate of the thorax mass and body mass.
\end{abstract}

\section{Introduction}

The accuracy of the evaluation of the body mass and center of mass for each body's segment with specific geometric parameters is needed for biomechanical analysis in orthopedics, sports medicine, athletics' performance and ergonomics, and vehicle's design and safety. Body segment parameters are computed from each segment's volume estimated from proportional and geometrics methods (Hanavan, 1964; Hatze, 1980; Yeadon, 1990) or from photogrammetry (Davidson et al., 2008; Jensen, 1978; Pillet et al., 2010; Young et al., 1983), radiography (Dumas et al., 2005; DuvalBeaupère and Robain, 1987; Zatsiorsky and Seluyanov, 1985), DXA (Lee et al., 2009), CT scans (Pearsall et al., 1996) and MRI (Bauer et al., 2007; Cheng et al., 2000). To determine body segment's mass and center of mass, the density for each segment is needed. Past studies widely used uniform densities based on studies on cadavers immersed in water (Chandler et al., 1975; Dempster, 1955). The principal limitation with cadaver studies is the representation of a specific population group of elderly males which may differ from other subgroups body's densities such as young adults or females, and the poor size of the populations studied. For example, Chandler et al. presented results from 6 cadavers (mean age unknown) (Chandler et al., 1975) vs 8 cadavers for Dempster et al. (mean age 72 years old (SD: 11)) (Dempster, 1955). The second limitation in immerging cadaver parts in water is omitting the air in the lungs in the density determination of the thorax. Most recent studies that investigated the mass and density of the thorax in vivo using MRI (Pearsall et al., 1994) or computed tomography (Pearsall et al., 1996) in the supine position highlighted inter-subject variability. Therefore, discrepancy exists in the definition of the thorax mass in term of percentage of the body mass ranging from 11\% (Dempster, 1955) to 29.4\% (Duval-Beaupère and Robain, 1987) and in density determination ranging from 0.82 
(Pearsall et al., 1994) to $0.92 \mathrm{~g} / \mathrm{cm}^{3}$ (Dempster, 1955). Variation in population samples (age, gender, body type) can have an effect on the prediction of the thorax mass and density. Therefore there is a need for a new method to determine subject specific thorax density (and therefore mass) for each individual.

A new low-dose imaging system taking bi-planar radiographies (Dubousset et al., 2010) combined with 3D reconstruction technique of the external body shape (Nérot et al., 2015), spine (Humbert et al., 2009) and of rib cage (Aubert et al., 2014) allows for volume estimation. Densities for each thorax tissues and segment have been well documented in the literature (Dempster, 1955; Erdmann and Gos, 1990; Hayashi et al., 2011; Li et al., 2010). The aim of this study was to combine those existing data to propose a new estimation of the thorax density.

\section{Methods}

\subsection{Participants}

58 asymptomatic participants ( 37 men, 21 women) were included in the study with a mean age of 35.5 years old [20-72 years old] and a mean body mass index (BMI) of $23.7 \mathrm{~kg} / \mathrm{m}^{2}\left[17.2-30.5 \mathrm{~kg} / \mathrm{m}^{2}\right]$. Participants were excluded if they presented spine pathologies or instrumentation anywhere in the upper body. All participants completed an informed consent document approved by the ethical committee of Hôpital Pitié Salpêtrière (Paris, France) (ethical committee approval CPP 06036). Participants were divided into 2 groups. Group A included 48 participants (33 men, 15 women): mean age of 37.3 years old [20-72 years old] and a mean body mass index (BMI) of $23.8 \mathrm{~kg} / \mathrm{m}^{2}\left[17.2-30.5 \mathrm{~kg} / \mathrm{m}^{2}\right]$. Group B included 10 participants ( 4 men, 6 women): mean age of 27.0 years old [21-33 years old] and a mean body mass index (BMI) of $23.7 \mathrm{~kg} / \mathrm{m}^{2}\left[20.0-29.5 \mathrm{~kg} / \mathrm{m}^{2}\right]$.

\subsection{Quantification of the thorax mass}

Low-dose bi-planar X-rays were acquired for all participants using the $\operatorname{EOS}^{\mathbb{R}}$ system (EOS imaging, Paris, France) which can simultaneously take a pair of X-rays from head to feet in the sagittal and frontal planes in upright position (Dubousset et al., 2010). These bi-planar radiographies allow three dimensional (3D) reconstructions of the bones and human body shape using well documented models (Aubert et al., 2014; Humbert et al., 2009; Nérot et al., 2015) (Figs. 1 and 2). The spine, rib cage and body shape were reconstructed for all participants. Body shape reconstruction was based on the deformation of a template which had been preliminarily segmented into 15 body segments, based on reference radiographs (Nérot et al., 2015). During the envelope reconstruction process, the template was morphed to match the skin contours on the orthogonal radiographs and body segments were thereby adjusted to the anthropometry of the subject on the radiographs (by scaling using bony points, and surface deformation algorithm) (Nérot et al., 2015). The thorax was defined from templates' mesh proximal and distal limits with axilla as limits on the sides. The proximal limit was taken as the edge loop that best fits the basis of the neck along the rectangular mesh topology. Similarly, the distal limit was taken as the edge loop that best fits rib 10 (last "false rib", connected to cartilage of rib 7) along the rectangular mesh topology. The subject-specific volume of this body segment was calculated from the external envelope reconstruction. Rib cage volume from rib 1 to 10 was computed including the sternum.

Three methods used to compute the thorax mass $\left(M^{\mathrm{T}}\right)$ were compared for Group A and tested on Group B in terms of total body mass and center of pressure, against forceplate data: (1) the Dempster Uniform Density Method using Dempster density data (Dempster, 1955) $\left(M_{\text {Dem }}^{\mathrm{T}}\right),(2)$ the Personalized Method using fulldescription of the thorax components based on 3D reconstruction of the body shape, the spine and the rib cage $\left(M_{\text {Perso }}^{\mathrm{T}}\right)$ and (3) the Improved Uniform Density Method using a uniform thorax density $\left(M_{\mathrm{Imp}}^{\mathrm{T}}\right)$.

\subsubsection{Dempster Uniform Density Method}

The Dempster Uniform Density Method is based on the density the most widely used in the literature for body segment density approximation which was described by Dempster in 1955 (Dempster, 1955). The Dempster Uniform Density Method computed the thorax mass $\left(M_{\text {Dem }}^{\mathrm{T}}\right)$ from the thorax volume $\left(V_{\text {thorax }}\right)$ determined from the body shape 3D reconstruction and Dempster thorax density $\left(D_{\text {thorax }}=0.92 \mathrm{~g} / \mathrm{cm}^{3}\right)$. The thorax mass was computed as shown in Eq. (1).

$M_{\text {Dem }}^{\mathrm{T}}=V_{\text {thorax }} * D_{\text {thorax }}$

\subsubsection{Personalized Method based on $3 D$ reconstructions}

The Personalized Method computed the thorax mass $\left(M_{\text {Perso }}^{\mathrm{T}}\right)$ by distinguishing different parts in the thorax. The rib cage volume $\left(V_{\text {ribcage }}\right)$ was considered as containing the heart volume ( $\left.V_{\text {heart }}\right)$, the lungs volume $\left(V_{\text {lung }}\right)$ and the volume of the following bones $\left(V_{\text {bone }}\right)$ : T1-T12 vertebrae $\left(V_{\text {Vert_Ti }} i=1-12\right)$, the sternum and the 10 right and left ribs. The other tissues in the thorax, outside of the rib cage, were considered as soft tissues.

The heart volume $\left(V_{\text {heart }}\right)$ was computed in $\mathrm{cm}^{3}$ from the age of the subject (Age) for both genders (Badouna et al., 2012) according to Eqs. (2) and (3).

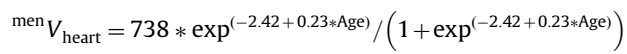
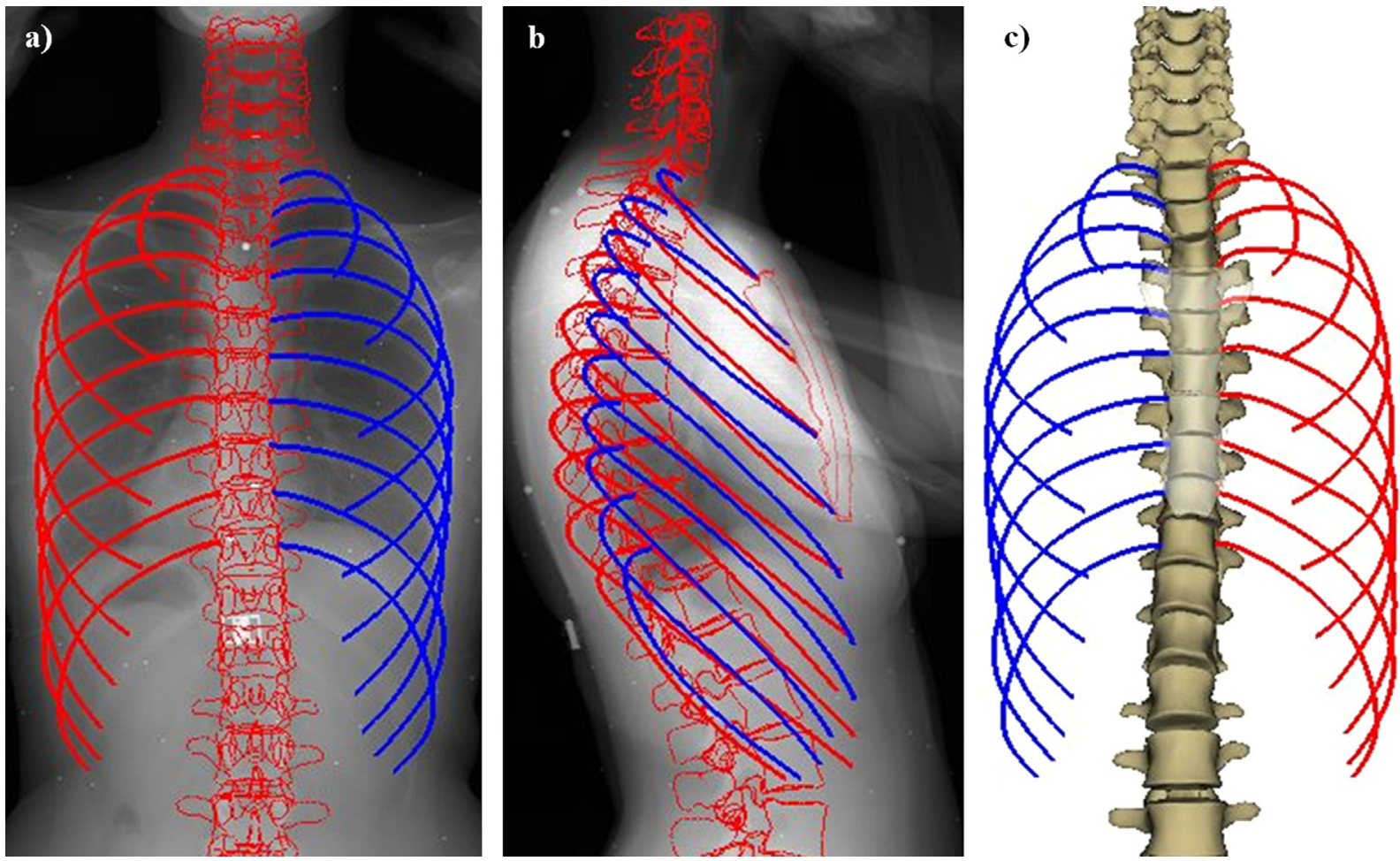

Fig. 1. 3D reconstruction of the rib cage. (a) and (b) Bi-planar radiographies with reconstructed spine and rib cage. (c) 3D reconstruction of the spine and rib cage. 

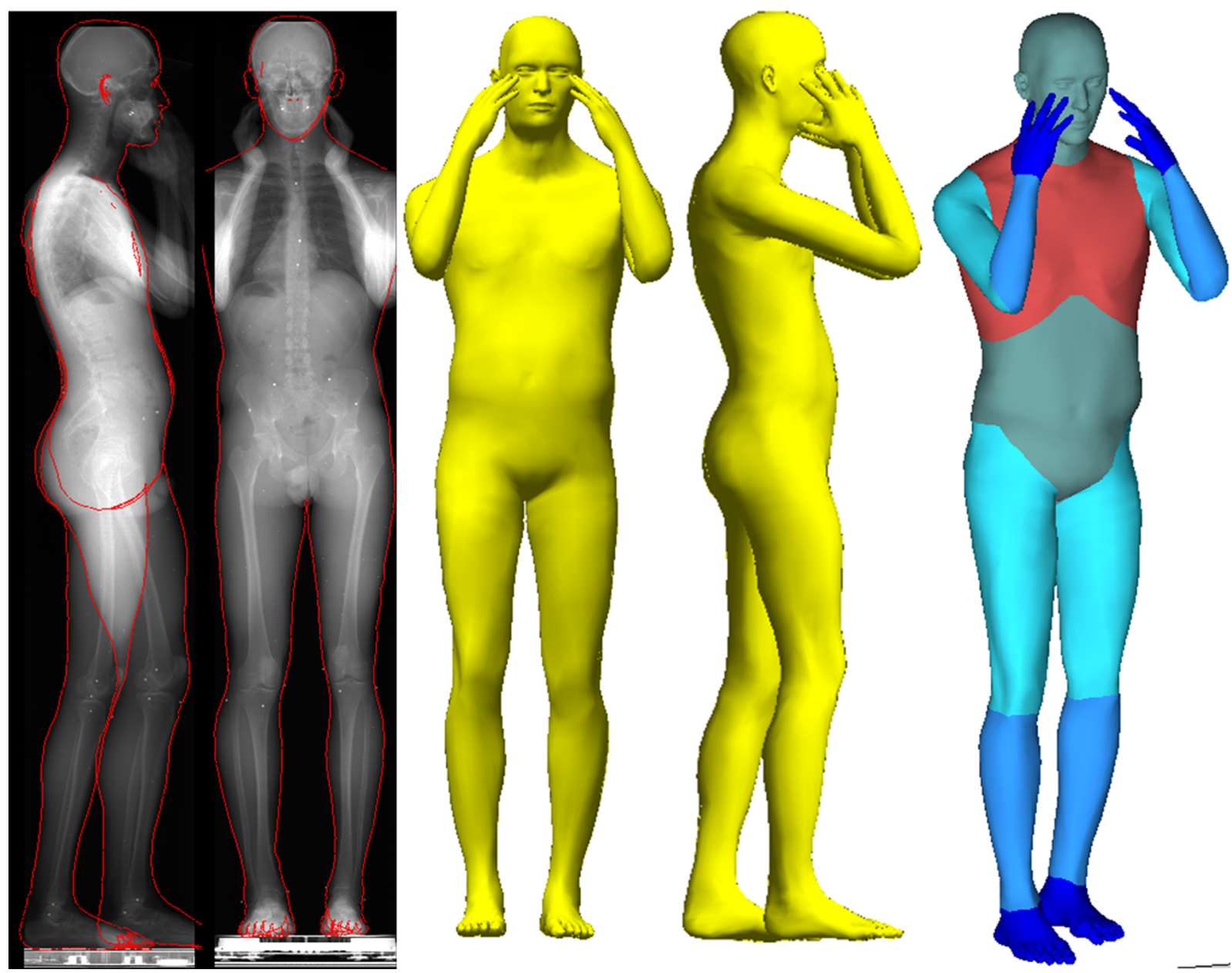

Fig. 2. 3D reconstruction of the body shape: projections on the bi-planar radiographies and 3D reconstruction of the body shape with the 15 considered segments (thorax highlighted in red). (For interpretation of the references to color in this figure legend, the reader is referred to the web version of this article.)

Table 1

Means and standard deviations of the volumes (for Group A) used to compute the thorax mass, and density applied to each volume (Dempster 1955; Li et al. 2010; Shirotani 1988). F: Female; M: Male.

\begin{tabular}{lrrrrl}
\hline & Mean volume $\mathbf{( c m 3 )}$ & $\begin{array}{l}\text { SD of the volume } \\
\left(\mathbf{c m}^{\mathbf{3}}\right)\end{array}$ & $\begin{array}{l}\text { Density } \\
\text { applied } \\
\left(\mathbf{g} / \mathbf{c m}^{\mathbf{3}}\right)\end{array}$ \\
\hline Gender & $F(n=15)$ & $M(n=33)$ & $F(n=15)$ & $M(n=33)$ & $\begin{array}{l}F \text { and } M \\
(n=48)\end{array}$ \\
Thorax & 13310.6 & 20341.5 & 2327.0 & 3330.9 & - \\
$\begin{array}{l}\text { Rib cage } \\
\text { Lungs }\end{array}$ & 5912.6 & 8581.7 & 850.9 & 1162.1 & - \\
$\begin{array}{l}\text { Ribs cortical } \\
\text { bone }\end{array}$ & 4874.8 & 7294.9 & 824.0 & 1138.9 & 0.28 \\
$\begin{array}{l}\text { Ribs trabecular } \\
\text { bone }\end{array}$ & 137.4 & 155.6 & 5.6 & 8.3 & 2.00 \\
$\begin{array}{l}\text { Sternum } \\
\text { Heart }\end{array}$ & 47.6 & 53.9 & 1.9 & 2.9 & 1.00 \\
\hline
\end{tabular}

${ }^{\text {women }} V_{\text {heart }}=572 * \exp ^{(-2.10+0.21 * \text { Age })} /\left(1+\exp ^{(-2.10+0.21 * \text { Age })}\right)$

The heart was considered as a soft tissue for its density: $D_{\text {soft_tissues }}=1.03 \mathrm{~g} / \mathrm{cm}^{3}$ (Dempster, 1955).

Lung volume was computed as shown in Eq. (4).

$V_{\text {lung }}=V_{\text {ribcage }}-V_{\text {heart }}-V_{\text {bone }}$

During the X-ray acquisition, no breathing instruction was given to the participant. The density applied for the air volume in the lungs was $D_{\text {lung }}=0.28 \mathrm{~g} / \mathrm{cm}^{3}$ (Shirotani, 1988) (Table 1).
Bone volume was computed from the $3 \mathrm{D}$ reconstruction of the rib cage and spine. The reconstruction of the rib cage allows estimation of the volume of trabecular bone and of the cortical bone for each rib level and for each participant based on the rib length (Aubert et al., 2014) (Eq. (5)).

$V_{\text {bone }}=V_{\text {sternum }}+V_{\text {ribs_trabecular }}+V_{\text {ribs_cortical }}+n_{i=1, \ldots, 12}\left(V_{\text {Vert_Ti }}\right)$

Ribs' masses were computed using the following densities: $D_{\text {cortical bone }}=2.00 \mathrm{~g} / \mathrm{cm}^{3}$ and $D_{\text {trabecular_bone }}=1.00 \mathrm{~g} / \mathrm{cm}^{3}$ (Li et al., 2010). The vertebrae densities $\left(D_{\mathrm{Ti}} i=1-12\right)$ were differentiated depending on the gender and the age (Hayashi et al., 2011) (Table 2). The sternum density was set to $D_{\text {sternum }}=1.00 \mathrm{~g} / \mathrm{cm}^{3}$. Therefore, the bone mass $\left(M_{\text {bone }}\right)$, including the bone volume (Eq. (5)) and the bone densities mentioned above, was calculated as shown in Eq. (6).

$M_{\text {bone }}=\left(V_{\text {sternum }}+V_{\text {ribs_trabecular }}\right) * D_{\text {trabecular_bone }}+V_{\text {ribs_cortical }} * D_{\text {cortical_bone }}+\sum_{i=1, \ldots 12}\left(V_{\text {Vert_Ti }} * D_{\text {Ti }}\right)$

The thorax mass with the Personalized Method $\left(M_{\text {Perso }}^{\mathrm{T}}\right)$ was computed as in Eq. (7):

$M_{\text {Perso }}^{\mathrm{T}}=V_{\text {lung }} * D_{\text {lung }}+\left(\left(V_{\text {thorax }}-V_{\text {ribcage }}\right)+V_{\text {heart }}\right) * D_{\text {soft_tissues }}+M_{\text {bone }}$

With the purpose of developing an easier method to obtain the thorax mass, we computed a new average thorax density and predicted the rib cage volume from external data.

\subsubsection{Basic estimation for the routine use: Improved Uniform Density Method}

The Improved Uniform Density Method computed the thorax mass $\left(M_{\mathrm{Imp}}^{\mathrm{T}}\right)$ from its external volume $\left(V_{\text {thorax }}\right)$ and from a mean density computed from the Personalized Method ( $D_{\text {Thorax_Perso }}$ ) as shown in Eq. (8). This density was computed as the ratio between the thorax mass $\left(M_{\text {Perso }}^{\mathrm{T}}\right)$ determined in Eq. (7) and the thorax volume ( $\left.V_{\text {thorax }}\right)$ averaged for Group A's participants (Eq. (9)).

$M_{\mathrm{Imp}}^{\mathrm{T}}=V_{\text {thorax }} * D_{\text {Thorax_Perso }}$ 
Table 2

Means, for Group A, of the volumes of the vertebrae used to compute the thorax mass, and density applied to each vertebra (Hayashi et al., 2011). F: Female; M: Male.

\begin{tabular}{|c|c|c|c|c|c|c|c|c|c|c|c|c|c|c|}
\hline & Age (years old) & Gender (number of subjects) & T1 & T2 & T3 & T4 & T5 & T6 & T7 & T8 & T9 & T10 & T11 & T12 \\
\hline \multirow[t]{8}{*}{ Mean volume $\left(\mathrm{cm}^{3}\right)$} & \multirow[t]{2}{*}{-40} & $F(n=9)$ & 13.1 & 12.0 & 13.2 & 13.7 & 14.8 & 16.2 & 17.8 & 19.3 & 21.7 & 25.2 & 26.7 & 29.0 \\
\hline & & $M(n=22)$ & 18.4 & 18.3 & 18.3 & 18.4 & 19.7 & 21.8 & 23.6 & 24.7 & 27.8 & 31.3 & 34.1 & 37.4 \\
\hline & \multirow[t]{2}{*}{$41-55$} & $F(n=2)$ & 12.9 & 15.0 & 15.1 & 15.1 & 15.6 & 18.4 & 19.5 & 20.7 & 23.9 & 28.4 & 27.9 & 29.8 \\
\hline & & $M(n=5)$ & 20.8 & 21.1 & 22.8 & 24.4 & 24.9 & 27.8 & 32.2 & 33.1 & 36.7 & 40.9 & 46.4 & 49.8 \\
\hline & \multirow[t]{2}{*}{$56-70$} & $F(n=2)$ & 17.1 & 14.6 & 15.7 & 18.5 & 19.5 & 21.4 & 22.9 & 24.0 & 28.1 & 32.7 & 37.1 & 37.9 \\
\hline & & $M(n=2)$ & 17.7 & 18.2 & 18.6 & 20.7 & 22.9 & 26.0 & 27.6 & 30.8 & 33.0 & 35.3 & 39.4 & 43.0 \\
\hline & \multirow[t]{2}{*}{71} & $F(n=2)$ & 19.0 & 18.6 & 17.7 & 19.9 & 22.0 & 22.8 & 25.1 & 25.1 & 30.2 & 33.0 & 36.0 & 35.2 \\
\hline & & $M(n=4)$ & 20.5 & 18.8 & 20.4 & 18.3 & 20.2 & 23.5 & 25.3 & 28.6 & 31.8 & 36.7 & 37.9 & 43.0 \\
\hline \multirow[t]{8}{*}{ Density applied $\left(\mathrm{g} / \mathrm{cm}^{3}\right)$} & \multirow[t]{2}{*}{-40} & $F(n=9)$ & 0.24 & 0.22 & 0.22 & 0.21 & 0.21 & 0.20 & 0.20 & 0.19 & 0.20 & 0.20 & 0.19 & 0.18 \\
\hline & & $M(n=22)$ & 0.21 & 0.21 & 0.21 & 0.21 & 0.20 & 0.20 & 0.19 & 0.19 & 0.19 & 0.19 & 0.18 & 0.18 \\
\hline & \multirow[t]{2}{*}{$41-55$} & $F(n=2)$ & 0.21 & 0.20 & 0.20 & 0.20 & 0.19 & 0.18 & 0.17 & 0.17 & 0.18 & 0.17 & 0.16 & 0.15 \\
\hline & & $M(n=5)$ & 0.19 & 0.19 & 0.19 & 0.18 & 0.18 & 0.17 & 0.16 & 0.15 & 0.16 & 0.16 & 0.15 & 0.14 \\
\hline & \multirow[t]{2}{*}{$56-70$} & $F(n=2)$ & 0.17 & 0.16 & 0.16 & 0.16 & 0.15 & 0.14 & 0.14 & 0.13 & 0.14 & 0.13 & 0.12 & 0.11 \\
\hline & & $M(n=2)$ & 0.19 & 0.19 & 0.20 & 0.18 & 0.17 & 0.16 & 0.15 & 0.15 & 0.15 & 0.15 & 0.13 & 0.12 \\
\hline & \multirow[t]{2}{*}{71} & $F(n=2)$ & 0.14 & 0.14 & 0.13 & 0.12 & 0.11 & 0.11 & 0.10 & 0.10 & 0.10 & 0.10 & 0.09 & 0.08 \\
\hline & & $M(n=4)$ & 0.17 & 0.17 & 0.16 & 0.15 & 0.14 & 0.13 & 0.12 & 0.12 & 0.13 & 0.12 & 0.11 & 0.10 \\
\hline
\end{tabular}

$D_{\text {Thorax_Perso }}=\Sigma_{j=1, \ldots, 48}\left(M_{\text {Perso }}^{\mathrm{T}}(j) / V_{\text {thorax }}(j)\right) / 48$

\subsection{Evaluation of the methods}

2.3.1. Estimation of the body mass

As the thorax cannot be isolated, global body mass and center of pressure position were used as control parameters. For Group B, a force plate (Wii Balance Board (WBB), Nintendo, Kyoto, Japan) was placed in the EOS cabin during the stereoradiography acquisition and recorded the mass and center of pressure (CoP) during the acquisition time. The WBB has been shown to be comparable to other usual forceplates in terms of comparison of balance tests and in terms of CoP estimation as its estimation presents an error less than 3\% for both coordinates (Clark et al., 2010).

Body mass and center of pressure were computed for each of the three methods and compared. In order to compute these, the individual subject-specific volume and barycenter of each 15 body segment of the reconstructed envelopes were calculated. Densities determined by Dempster (Dempster, 1955) were used for all segments' mass calculation except for the arms and thorax. For the arms, using regressions from Dempster, their masses were computed using ratios of all other body segments' masses (Dempster, 1955). For the thorax, the three detailed methods were applied for determination of the thorax mass. Total body mass was computed as the sum of individual segments' masses. Center of pressure was computed as the weighted sum of segments' barycenters. Body mass and center of pressure were then compared for each method with the ones obtained from the WBB (considered as the gold standard) for Group B.

\subsubsection{Prediction of the rib cage volume, thorax mass and thorax volume}

Multi-linear regression was searched for to simplify computation of the rib cage volume from the reconstructed external thorax volume, the BMI, the Age and the Gender of the subject. Multi-linear regressions were computed using one or more of these regressors. Additional multi-linear regressions were searched for to estimate thorax mass (from the Personalized Method) and thorax volume from the $\mathrm{BMI}$, the age and gender to see if demographic parameters alone were sufficient to evaluate thorax parameters.

Evaluation of the rib cage volume, thorax mass and thorax volume estimations were made by calculating the leave-one-out-error (LOOE) (i.e. the regression model is built on all patients except one, and tested on this one, and this is made for all patients), the $R$-squared statistics $\left(R^{2}\right)$, the $p$-value ( $p$-val) and the standard error of estimate (SEE) for each multi-linear regression.

\section{Results}

\subsection{Quantification of the thorax mass}

Mean and standard deviation of the volumes of the considered bones and segments can be found in Tables 1 and 2 .

The mean density used in the Improved Uniform Density Method was $0.74 \mathrm{~g} / \mathrm{cm}^{3}$ (SD: $0.03 \mathrm{~g} / \mathrm{cm}^{3}$ ) for men and $0.73 \mathrm{~g} / \mathrm{cm}^{3}$ (SD: $0.03 \mathrm{~g} / \mathrm{cm}^{3}$ ) for women.

Mean and standard deviations of the thorax mass computed with the three Methods can be found in Table 3. The mean difference between the thorax mass determined with the
Table 3

Means, standard deviations and range of the thorax mass (in $\mathrm{kg}$ ) obtained with the Dempster Uniform Density, Personalized and Improved Uniform Density Methods for Group A.

\begin{tabular}{|c|c|c|c|c|}
\hline \multirow[b]{2}{*}{ Thorax Mass } & \multicolumn{2}{|c|}{ Male subjects (kg) } & \multicolumn{2}{|c|}{ Female subjects (kg) } \\
\hline & Mean (1*SD) & $\begin{array}{l}\text { 95\% Con- } \\
\text { fidence } \\
\text { interval }\end{array}$ & Mean $\left(1^{*} S D\right)$ & $\begin{array}{l}\text { 95\% Con- } \\
\text { fidence } \\
\text { interval }\end{array}$ \\
\hline $\begin{array}{l}\text { Dempster Uni- } \\
\text { form Density } \\
\text { Method }\end{array}$ & $18.7(3.1)$ & {$[12.6 ; 24.8]$} & $12.2(2.1)$ & {$[8.0 ; 16.5]$} \\
\hline $\begin{array}{l}\text { Personalized } \\
\text { Method }\end{array}$ & $15.1(2.7)$ & {$[9.6 ; 20.5]$} & $9.7(1.9)$ & {$[6.0 ; 13.5]$} \\
\hline $\begin{array}{l}\text { Improved Uni- } \\
\text { form Density } \\
\text { Method }\end{array}$ & $15.1(2.5)$ & {$[10.1 ; 20.0]$} & $9.7(1.7)$ & {$[6.3 ; 13.1]$} \\
\hline
\end{tabular}

Personalized Method (respectively the Improved Uniform Density Method), and the thorax mass calculated with the Dempster Uniform Density Method, was $3.3 \mathrm{~kg}$ (SD: 0.8 ) (respectively $3.3 \mathrm{~kg}$ (SD: 0.8)). The mean difference between the thorax mass determined with the Personalized Method and calculated with the Improved Uniform Density Method was $0.0 \mathrm{~kg}$ (SD: 0.5) (Fig. 3).

\subsection{Evaluation of the methods}

\subsubsection{Estimation of the body mass and CoP}

Individual differences between the body masses given by the WBB, the Dempster Uniform Density Method, the Personalized Method, and the Improved Uniform Density Method are displayed, for Group B, in Fig. 4. For Group B, the average body mass was $71.0 \mathrm{~kg}$ (SD: 15.0) from the WBB, and $74.4 \mathrm{~kg}$ (SD: 15.6); $71.1 \mathrm{~kg}$ (SD: 14.8 ) and $71.3 \mathrm{~kg}$ (SD: 14.8) using the Dempster Uniform Density Method, the Personalized Method and the Improved Uniform Density Method respectively.

Differences between the CoP positions estimated by the Dempster Uniform Density Method, the Personalized Method and the Improved Uniform Density Method, compared to the WBB data were less than $4.8 \mathrm{~mm}$ (Table 4 ).

\subsubsection{Prediction of the rib cage volume, thorax mass and thorax volume from multi-linear regressions}

The model predicting the rib cage volume and presenting the smallest Leave-One-Out-Error (LOOE: $7.8 \%$ of the mean rib cage volume), the greatest $R^{2}(0.88)$ and the lowest Standard Error of the Estimate (SEE: $7.2 \%$ of the mean rib cage volume) was the one using 


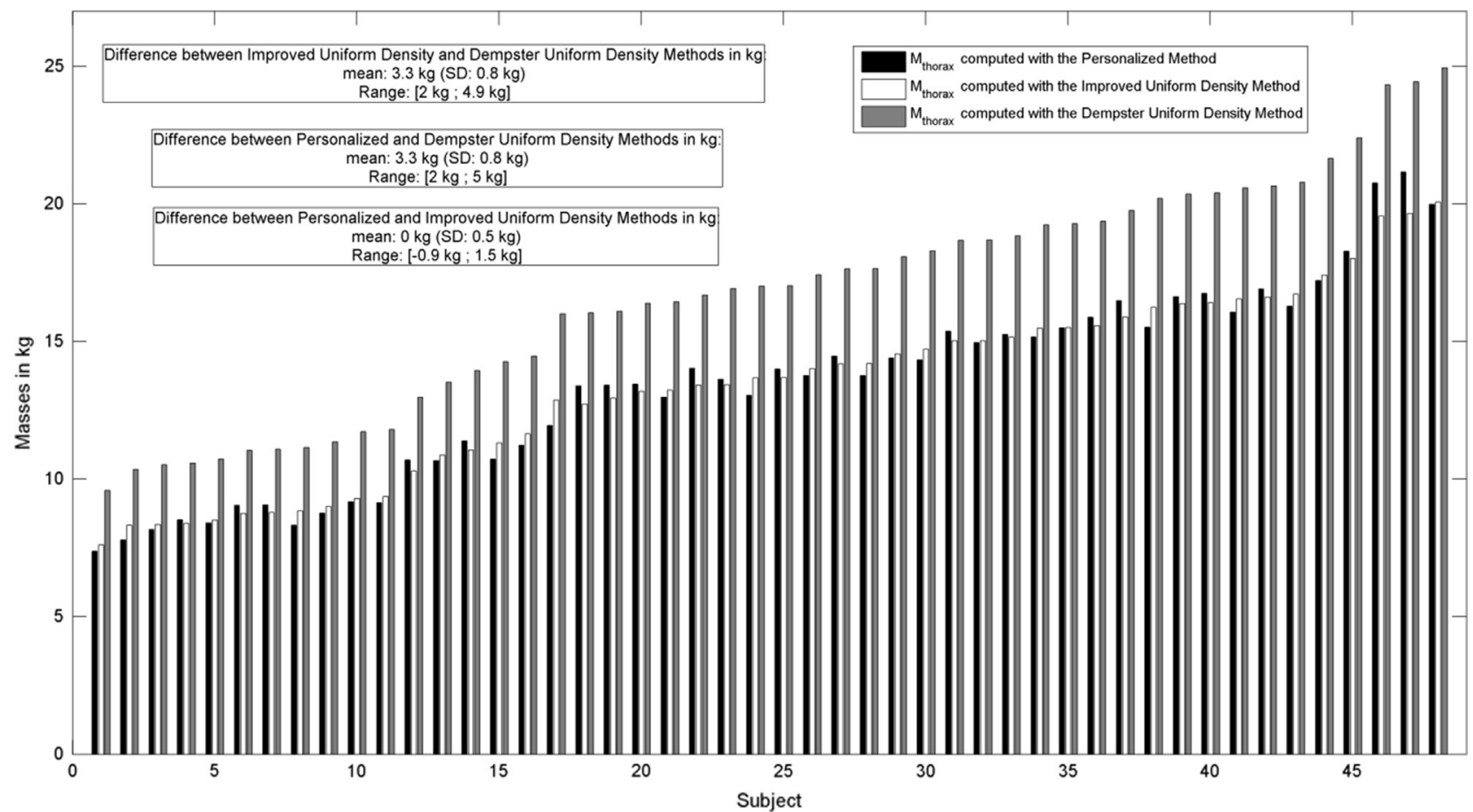

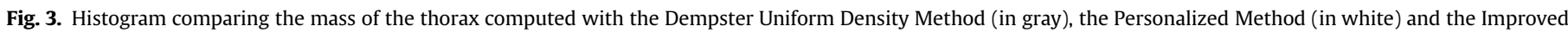
Uniform Density Method (in black), for Group A.

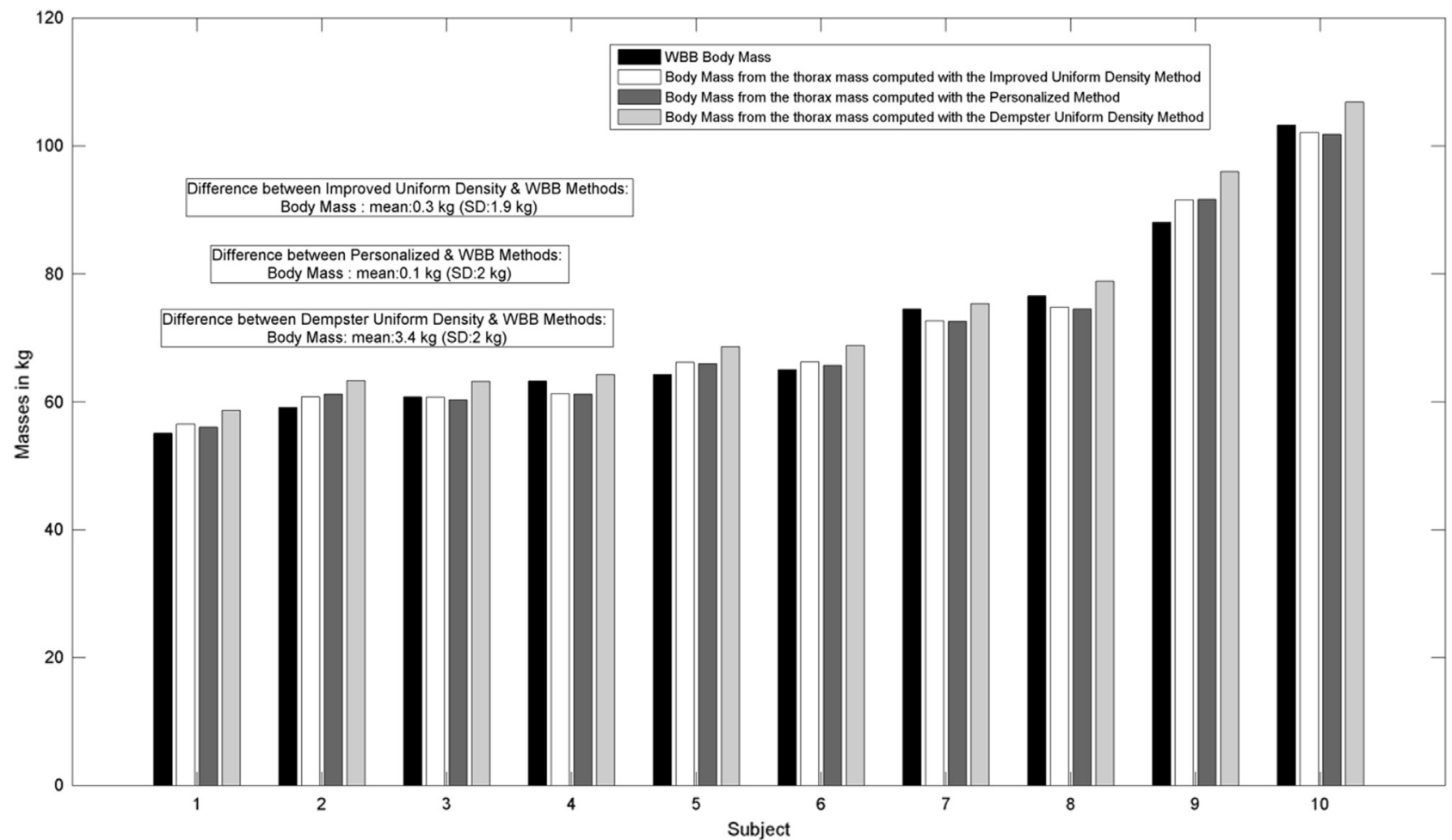

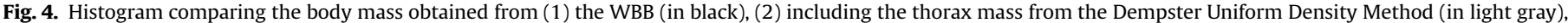

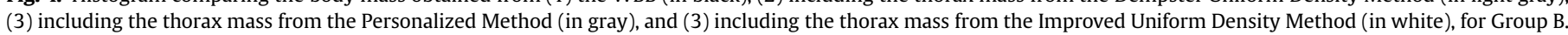

2 regressors (reconstructed external thorax volume $\left(V_{\text {thorax }}\right)$ and Gender ( 0 for women and 1 for men)). The prediction of the rib cage volume ( ${ }^{\mathrm{reg}} V_{\text {ribcage }}$ in $\mathrm{cm}^{3}$ ) based on the 2 regressors was significant $(p<0.05)$ and relies on Eq. (10).

${ }^{\text {reg }} V_{\text {ribcage }}=0.298 * V_{\text {thorax }}+572.7 *$ Gender +1943.6 
Table 4

Mean $(1 * \mathrm{SD})[\mathrm{min} ; \max ]$ of the differences between the CoP position evaluated by the WBB $\left(\mathrm{CoP}_{\text {wii }}\right)$, the Dempster Uniform Density Method $\left(\mathrm{CoP}_{\text {Dem }}\right)$, the Personalized Method ( $\mathrm{CoP}_{\text {Perso }}$ ) and the Improved Uniform Density Method ( $\left.\mathrm{CoP}_{\mathrm{Imp}}\right)$; for Group B.

\begin{tabular}{|c|c|c|c|}
\hline & $\begin{array}{l}X \text { : postero-anterior } \\
\text { direction }(\mathrm{mm})\end{array}$ & $\begin{array}{l}\text { Y: medio-lateral } \\
\text { direction (mm) }\end{array}$ & Norm (mm) \\
\hline CoP $_{\text {Dem}}-C_{\text {- }} P_{\text {wii }}$ & $-0.7(4.7)[-9.5 ; 4.5]$ & $1.8(1.8)[-1.8 ; 3.9]$ & $\begin{array}{l}4.4(2.7)[0.2 ; \\
9.6]\end{array}$ \\
\hline $\begin{array}{l}\text { CoP }_{\text {Perso- }} \\
\text { CoP }_{\text {wii }}\end{array}$ & $0.8(5.0)[-8.6 ; 6.5]$ & $1.5(1.9)[-2.1 ; 3.6]$ & $\begin{array}{l}4.8(2.5)[1.0 ; \\
8.7]\end{array}$ \\
\hline $\mathrm{CoP}_{\text {Imp }}-\mathrm{CoP}_{\text {wii }}$ & $0.7(4.9)[-8.4 ; 6.4]$ & $1.5(1.9)[-2.1 ; 3.7]$ & $\begin{array}{l}4.7(2.5)[1.0 ; \\
8.5]\end{array}$ \\
\hline
\end{tabular}

This equation was tested on the Group B and differences between the predicted rib cage volume and the reconstructed rib cage volume was in average $-4.2 \%$ (SD: 5.9 ) of the mean rib cage volume.

The best predictors of the thorax volume and mass were the age, BMI and gender respectively leading to a LOOE of $12.1 \%$ and $14.1 \%$; and to a SEE of $11.2 \%$ and $13.0 \%$ (both in \% of the mean thorax mass or thorax volume) with high determination coefficient (Table 5). Thorax volume regression analysis was tested on the Group B and difference between the 3D reconstructed thorax volume and the predicted thorax volume was in average $5 \%$ of the mean thorax volume (SD: $11.5 \%)$. Thorax mass regression analysis was also tested on Group B and difference between the predicted thorax mass and the thorax mass determined with the Personalized Method was 3.8\% of the mean thorax mass of the Personalized Method (SD: $12.5 \%$ ).

\section{Discussion}

The purpose of this study was to propose an improved uniform thorax density representative of the living population from 3D external body shape modeling. The currently used method (Dempster Uniform Density Method) was compared to two newly presented methods (Personalized and Improved Uniform Density Methods) for the thorax mass computation. The Improved Uniform Density Method introduced a new uniform density $\left(0.73 \mathrm{~g} / \mathrm{cm}^{3}\right.$ and $0.74 \mathrm{~g} / \mathrm{cm}^{3}$ vs $0.92 \mathrm{~g} / \mathrm{cm}^{3}$ for Dempster (Dempster, 1955)). This method is a compromise between accuracy and ease to implement: it is less complex to use but as accurate as the method considered as reference here: the Personalized Method.

The three methods were evaluated on Group A for calculation of the thorax mass based on the thorax volume and density. Overall, the Dempster Uniform Density Method over-estimated the thorax mass compared to the Personalized Method and the Improved Uniform Density Method. The main reason for this over-estimation is the change in thorax density between cadavers (Dempster Uniform Density Method) and living population (Personalized and Improved Uniform Density Method) due to the lung tissue. Reported lung densities on cadavers ranged from $0.563 \mathrm{~g} / \mathrm{cm}^{3}$ (Erdmann and Gos, 1990) to $1.050 \mathrm{~g} / \mathrm{cm}^{3}$ (Woodard and White, 1986) while in vivo measures were found to be $0.254 \mathrm{~g} / \mathrm{cm}^{3}$ during expiration
(Kohda and Shigematsu, 1989) and the mean lung density used for the Personalized method was $0.28 \mathrm{~g} / \mathrm{cm}^{3}$. Therefore, in vivo density of the thorax computed with the Personalized Method was in average lower than the density calculated by Dempster (Dempster, 1955) and used in the Dempster Uniform Density Method. The thorax density reported from in vivo studies on four adults using CT scan (Pearsall et al., 1996) and on 26 males using MRI (Pearsall et al., 1994) can vary substantially from $0.73-0.74 \mathrm{~g} / \mathrm{cm}^{3}$ in our study to $0.82 \mathrm{~g} / \mathrm{cm}^{3}$ (Pearsall et al., 1994) and $0.87 \mathrm{~g} / \mathrm{cm}^{3}$ (Pearsall et al., 1996). These differences can be attributed to variation in measurement techniques and in the population studied. A large range of males and females population ranging from 20 to 72 years old was considered in the present study while others used only males or just few individuals. Therefore discrepancies exist in the estimation of the thorax mass between in vivo studies ranging from $9.99 \mathrm{~kg}$ (Jensen and Fletcher, 1994) to $20.48 \mathrm{~kg}$ (Duval-Beaupère and Robain, 1987). The Personalized Method approximated an average thorax mass of $9.7 \mathrm{~kg}$ for females and $15.1 \mathrm{~kg}$ for males which is in the range of what was previously published (Duval-Beaupère and Robain, 1987; Jensen and Fletcher, 1994; Pearsall et al., 1996, 1994). In order to validate the new thorax density, choice was made to compare center of pressure and total body mass using the different methods to compute the thorax mass against forceplate data, for each subject of Group B. While thorax mass will be different for each method, the 14 other segments' mass used to compute the total body mass are based on Dempster density (Dempster, 1955) and the 3D body envelope for volume calculation. That way the only variant in the total body mass and COP calculation for each method is the thorax density. Despite its limitations, this validation method was considered as a realistic option available for evaluation. Further validation could consider in vivo calibrated whole body CT scans, but such data is difficult to obtain because of irradiation issues. Volumetric techniques tended to over-estimate the whole body mass which may be attributed to the use of uniform segment density from cadaver studies such as Dempster (body mass error estimation of $3.4 \mathrm{~kg}$ in average). Body mass estimation error could vary from $0.2 \%$ to $5.9 \%$ on young volunteers (Pillet et al., 2010) and from $1.1 \%$ to $4.6 \%$ on children and adults males (Sandoz et al., 2010). A mean error of $4.8 \%$ [1.2-11.2\%] in the total body mass was found in the present study using the Dempster Uniform Density Method which is concordant with the previous studies (Pillet et al., 2010; Sandoz et al., 2010). These results demonstrated the need to incorporate improved density profiles representative of the living population. The Personalized Method used detailed differentiation in the thorax entities' volumes and densities and found a total body mass error of only $0.2 \%$. However this method requires reconstructing the rib cage and spine which can be long and intricate. That is why the present study proposed the Improved Uniform Density Method based on a new average thorax density applicable to all in vivo studies. A body mass error of $0.4 \%$ was found between the Improved Uniform Density Method and the WBB. This error is less than the Dempster Uniform Density Method and equivalent to the Personalized Method. This new thorax density of $0.74 \mathrm{~g} / \mathrm{cm}^{3}$ for men and $0.73 \mathrm{~g} / \mathrm{cm}^{3}$ for women presented here showed a good estimation of the overall body mass. Moreover, a low SD of $0.03 \mathrm{~g} / \mathrm{cm}^{3}$ for both genders demonstrated that the density does not vary much between individuals. Therefore, when computing the

Table 5

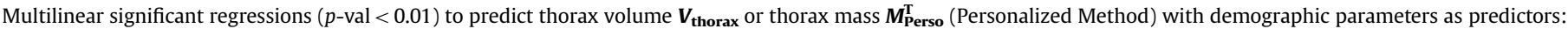
Age (years), BMI $\left(\mathrm{kg} / \mathrm{m}^{2}\right)$, Gender ( 0 for Female and 1 for Male).

\begin{tabular}{|c|c|c|}
\hline Value to predict & Correlation coefficient: $R^{2}$ & Equation \\
\hline $\begin{array}{l}\text { Thorax volume } \boldsymbol{V}_{\text {thorax }}\left(\mathrm{cm}^{3}\right) \\
\text { Thorax mass } \boldsymbol{M}_{\text {Perso }}^{\mathbf{T}}(\mathrm{kg})\end{array}$ & $\begin{array}{l}0.79 \\
0.75\end{array}$ & $\begin{array}{l}\boldsymbol{V}_{\text {thorax }}=\left(-4.94+0.01^{*} \text { Age }+0.76^{*} \mathbf{B M I}+6.55^{*} \text { Gender }\right)^{*} 10^{6} \\
\boldsymbol{M}_{\text {Perso }}^{\mathrm{T}}=-4.65+0.01^{*} \text { Age }+0.60^{*} \mathbf{B M I}+4.96^{*} \text { Gender }\end{array}$ \\
\hline
\end{tabular}


thorax mass, the thorax volume remains the most inter-subject variable parameter compared to the density.

The CoP was also estimated using the three methods and compared to the force plate. All methods gave a CoP error less than $4.8 \mathrm{~mm}$ which is in the range of the WBB magnitude error (Clark et al., 2010). The Thorax density used to approximate the CoP did not influence on the determination of the CoP of asymptomatic adults. However these errors might change if the estimation was made on a population with postural disorders, especially patients with hyper kyphosis.

For investigators who wish to estimate a subject specific thorax density by differentiating the lungs density in the rib cage, the present study proposed rib cage volume estimation from the volume of the thorax and gender. The estimated rib cage volume approximated the reconstructed rib cage volume very well with a mean error of $-4.2 \%$ for Group B. Moreover, the present study used multi-linear regression analysis to estimate thorax volume and thorax mass from easily available demographic parameters such as age, gender and BMI. However this regression analysis could only predict thorax volume and mass with errors respectively of $11.2 \%$ and $13.0 \%$ (SEE errors) when compared to the real thorax volume from 3D thorax reconstruction and to the thorax mass estimated with the Personalized method.

This study's novelty resides in the differentiation of the lungs and heart, in the computation of the thorax density. Other segments' densities were not considered in this study as all of them, except the abdomen, are mainly composed of fat, muscle and bone. The thorax density only was considered for improvements in this study to focus on the influence of the air present in the lungs on the thorax density in the living population. Further improvements could include the liver and the shoulder girdle in the thorax description, and a more accurate sternum's density. Such enhancements are not straight forward as these organs/bones have subject variable masses and positions in the thorax. However, the authors are confident that these limitations will not significantly influence the total body mass as the present estimation of the total body mass is more realistic than the conventional one provided by Dempster (Dempster, 1955). No breathing instruction was given to the participants during the X-ray acquisition, as with the acquisition time of $30 \mathrm{~s}$, participants were not able to hold their breath. Another limitation of the presented study resides in the use of constants/equations to predict for example the heart volume (Badouna et al., 2012), and the vertebrae densities (Hayashi et al., 2011), which could contribute to the uncertainty of the estimated thorax mass. Nevertheless, despite these approximations, the Personalized Method provides a total body mass more accurate than the one computed with the Dempster Uniform Density Method (Dempster, 1955) (mean difference with the WBB total body mass: $0.1 \mathrm{~kg}$ vs $3.4 \mathrm{~kg}$ (Fig. 4)). Therefore what seems important is to differentiate thorax structures of very different densities such as lungs and heart. While such detailed modeling could be uneasy to implement in routine studies, the Improved Uniform Density Method appears as a relevant alternative being as accurate and less complex. This reinforces the validity of the newly found thorax density, as it accounts for various approximations, and is still little variable between subjects. The last limitation of this study is the inability to validate the thorax mass estimation. However, total body mass was computed with the same body segments' densities except for the thorax, therefore differences observed, in the total body masses, come from differences in the thorax density.

Overall, this study provides a new density for the thorax segment $\left(0.74 \mathrm{~g} / \mathrm{cm}^{3}\right.$ for men and $0.73 \mathrm{~g} / \mathrm{cm}^{3}$ women $)$ instead of the one provided by Dempster $\left(0.92 \mathrm{~g} / \mathrm{cm}^{3}\right)$. This density leads to a better estimate of the thorax mass and therefore of the body mass from body segments' volume.

\section{Conflict of interest statement}

The authors have no conflicts of interest to declare.

\section{Acknowledgments}

The authors are grateful to the Banque Public d'Investissement for financial support through the dexEOS project part of the French FUI14 program. The authors also thank the ParisTech BiomecAM chair program on subject-specific musculoskeletal modeling, and in particular COVEA and Société Générale.

\section{References}

Aubert, B., Vergari, C., Ilharreborde, B., Courvoisier, A., Skalli, W., 2014. 3D reconstruction of rib cage geometry from biplanar radiographs using a statistical parametric model approach. Comput. Methods Biomech. Biomed. Eng. Imaging Vis., 1-15. http://dx.doi.org/10.1080/21681163.2014.913990.

Badouna, A.N.I., Veres, C., Haddy, N., Bidault, F., Lefkopoulos, D., Chavaudra, J., Bridier, A., de Vathaire, F., Diallo, I., 2012. Total heart volume as a function of clinical and anthropometric parameters in a population of external beam radiation therapy patients. Phys. Med. Biol. 57, 473-484. http://dx.doi.org/ 10.1088/0031-9155/57/2/473.

Bauer, J.J., Pavol, M.J., Snow, C.M., Hayes, W.C., 2007. MRI-derived body segment parameters of children differ from age-based estimates derived using photogrammetry. J. Biomech. 40, 2904-2910. http://dx.doi.org/10.1016/j.jbiomech.2007.03.006.

Chandler, R.F., Clauser, C.E., Mcconville, J.T., Reynolds, H., Young, J., 1975. Investigation of Intertial Properties of the Human Body.

Cheng, C.K., Chen, H.H., Chen, C.S., Lee, C.L., Chen, C.Y., 2000. Segment inertial properties of Chinese adults determined from magnetic resonance imaging. Clin. Biomech. 15, 559-566. http://dx.doi.org/10.1016/S0268-0033(00)00016-4.

Clark, R.A., Bryant, A.L., Pua, Y., McCrory, P., Bennell, K., Hunt, M., 2010. Validity and reliability of the nintendo Wii balance board for assessment of standing balance. Gait Posture 31, 307-310. http://dx.doi.org/10.1016/j.gaitpost.2009.11.012.

Davidson, P.L., Wilson, S.J., Wilson, B.D., Chalmers, D.J., 2008. Estimating subjectspecific body segment parameters using a 3-dimensional modeller program. J. Biomech. 41, 3506-3510. http://dx.doi.org/10.1016/j.jbiomech.2008.09.021.

Dempster, W.T., 1955. Space Requirements of the Seated Operator. WADC Technical Report (TR-55-159). Wright Patterson Air Force Base. Ohio.

Dubousset, J., Charpak, G., Skalli, W., DeGuise, J.A., Kalifa, G., 2010. EOS: a new imaging system with low dose radiation in standing position for spine and bone \& joint disorders. J. Musculoskelet. Res. 13, 1-12.

Dumas, R., Aissaoui, R., Mitton, D., Skalli, W., de Guise, J.A., 2005. Personalized body segment parameters from biplanar low-dose radiography. IEEE Trans. Biomed. Eng. 52, 1756-1763.

Duval-Beaupère, G., Robain, G., 1987. Visualization on full spine radiographs of the anatomical connections of the centres of the segmental body mass supported by each vertebra and measured in vivo. Int. Orthop. 11, 261-269. http://dx.doi. org/10.1007/BF00271459.

Erdmann, W.S., Gos, T., 1990. Density of trunk tissues of young and medium age people. J. Biomech. 23, 945-947. http://dx.doi.org/10.1016/0021-9290(90) 90360-F.

Hanavan, E.P., 1964. A mathematical model of the human body. AMRL-TR, 64-102 Aerospace.

Hatze, H., 1980. A mathematical model for the computational determination of parameter values of anthropomorphic segments. J. Biomech. 13, 833-843. http://dx.doi.org/10.1016/0021-9290(80)90171-2.

Hayashi, T., Chen, H., Miyamoto, K., Zhou, X., Hara, T., Yokoyama, R., Kanematsu, M. Hoshi, H., Fujita, H., 2011. Analysis of bone mineral density distribution at trabecular bones in thoracic and lumbar vertebrae using X-ray CT images. J. Bone Miner. Metab. 29, 174-185. http://dx.doi.org/10.1007/s00774-010-0204-1.

Humbert, L., de Guise, J. a, Godbout, B., Cresson, T., Branchaud, D., Chav, R., Gravel, P. Parent, S., Dubousset, J., Skalli, W., 2009. Fast 3D reconstruction of the spine from biplanar radiography: a diagnosis tool for routine scoliosis diagnosis and research in biomechanics. Comput. Methods Biomech. Biomed. Eng. 12, 151-163. http://dx.doi.org/10.1080/10255840903081222.

Jensen, R.K., 1978. Estimation of the biomechanical properties of three body types using a photogrammetric method. J. Biomech. 11, 349-358. http://dx.doi.org/ 10.1016/0021-9290(78)90069-6.

Jensen, R.K., Fletcher, P., 1994. Distribution of mass to the segments of elderly males and females. J. Biomech. 27, 89-96. http://dx.doi.org/10.1016/0021-9290(94) 90035-3.

Kohda, E., Shigematsu, N., 1989. Measurement of lung density by computed tomography: implication for radiotherapy. Keio J. Med. 38, 454-463.

Lee, M.K., Le, N.S., Fang, A.C., Koh, M.T.H., 2009. Measurement of body segment parameters using dual energy X-ray absorptiometry and three-dimensiona geometry: An application in gait analysis. J. Biomech. 42, 217-222. http://dx. doi.org/10.1016/j.jbiomech.2008.10.036. 
Li, Z., Kindig, M.W., Subit, D., Kent, R.W., 2010. Influence of mesh density, cortical thickness and material properties on human rib fracture prediction. Med. Eng. Phys. 32, 998-1008. http://dx.doi.org/10.1016/j.medengphy.2010.06.015.

Nérot, A., Choisne, J., Amabile, C., Travert, C., Pillet, H., Wang, X., Skalli, W., 2015. A 3D reconstruction method of the body envelope from biplanar X-rays: evaluation of its accuracy and reliability. J. Biomech. 48, 4322-4326. http://dx.doi. org/10.1016/j.jbiomech.2015.10.044.

Pearsall, D.J., Reid, J.G., Livingston, L.A., 1996. Segmental inertial parameters of the human trunk as determined from computed tomography. Ann. Biomed. Eng. 24, 198-210.

Pearsall, D.J., Reid, J.G., Ross, R., 1994. Inertial properties of the human trunk of males determined from magnetic resonance imaging. Ann. Biomed. Eng. 22, 692-706. http://dx.doi.org/10.1007/BF02368294.

Pillet, H., Bonnet, X., Lavaste, F., Skalli, W., 2010. Evaluation of force plate-less estimation of the trajectory of the centre of pressure during gait. Comparison of two anthropometric models. Gait Posture 31, 147-152. http://dx.doi.org/ 10.1016/j.gaitpost.2009.09.014.

Sandoz, B., Laporte, S., Skalli, W., Mitton, D., 2010. Subject-specific body segment parameters' estimation using biplanar X-rays: a feasibility study. Comput.
Methods Biomech. Biomed. Eng. 13, 649-654. http://dx.doi.org/10.1080/ 10255841003717608.

Shirotani, T., 1988. Realistic torso phantom for calibration of in-vivo transuranicnuclide counting facilities. J. Nucl. Sci. Technol. 25, 875-883. http://dx.doi.org/ 10.1080/18811248.1988.9735941.

Woodard, H.Q., White, D.R., 1986. The composition of body tissues. Br. J. Radiol. 59, 1209-1218.

Yeadon, M.R., 1990. The simulation of aerial movement - II. A mathematical inertia model of the human body. J. Biomech. 23, 67-74. http://dx.doi.org/10.1016/ 0021-9290(90)90370-I.

Young, J.W., Chandler, R.F., Ret, C.C.S., Robinette, K.M., Zehner, G.F., 1983. Anthropometric and Mass Distribution Characteristics of the Adult Female.

Zatsiorsky, V.M., Seluyanov, V.N., 1985. Estimation of the mass and inertie characteristics of the human body by means of the best predictive regression equations. Biomechanics, 233-239. 